\title{
Bedside Assessment of the Microvascular Venous Compartment in Cardiac Surgery Patients With Valvular Diseases Undergoing Cardiopulmonary Bypass
}

\author{
Roberto Alberto De Blasi, MD,* Stefano Romagnoli, MD,† and Monica Rocco, MD*
}

\begin{abstract}
Objective: Blood volume reserve for venous return and the effects of cardiopulmonary bypass (CPB) on microvascular bed partitioning and blood flow were examined in patients with valvular diseases.

Design: Prospective, consecutive, case-control study.

Setting: Single university hospital.

Participants: The study comprised 20 adult cardiac surgery patients and 20 healthy volunteers.

Interventions: Cardiovascular and microvascular variables were collected soon after the induction of anesthesia, after commencement of CPB, 20 minutes after separation from $\mathrm{CPB}$, and in the intensive care unit.

Measurements and Main Results: The unstressed and stressed volumes (Vu, Vs) and pressures therein (Pit, Ps) were measured in the brachioradial muscle with near-infrared spectroscopy, applying incremental venous occlusions. At the first time point, Vs and Pit showed lower and higher values, respectively, than those of control patients, but Vs increased with $\mathrm{Vu}$ during the study, whereas Pit remained
\end{abstract}

C ARDIOVASCULAR MONITORING normally is used to evaluate the relationship between cardiac load and output to maintain blood perfusion to organs and tissues. Cardiac surgery patients undergoing cardiopulmonary bypass (CPB) experience injury to organs and tissues in multiple systems. ${ }^{1-3}$ The effects of CPB add to the cardiovascular adaptations induced by underlying cardiac diseases. In particular, valvular diseases induce compensatory mechanisms, resulting in pressure adjustments in the intravascular compartments that aim to maintain venous return. ${ }^{4}$ Because approximately $80 \%$ of blood volume is present in veins and three-quarters of that is in small veins and venules, 5,6 the venous compartment of the microvascular bed plays a pre-eminent role in blood volumes and pressures, partitioning between the unstressed volume $(\mathrm{Vu})$ and the stressed volume (Vs), in determining the amount of venous return. Whereas the $\mathrm{Vu}$ is a reserve of blood volume that has only limited involvement in the blood volume expansion aimed at increasing cardiac output (CO), the Vs is involved actively in venous return and, consequently, cardiac preload. $^{8}$

As a result of the microcirculation's leading role in maintaining organ function, many authors have focused their research on the effect of $\mathrm{CPB}$ on the microcirculation. ${ }^{9-11}$ There is increasing evidence regarding $\mathrm{CPB}$-induced changes in microvascular blood flow, capillary density, tissue oxygenation, and mitochondrial dysfunction. ${ }^{12-16}$ However, there have been no clinical studies on the venous compartment of the microvascular bed and how it might be affected by $\mathrm{CPB}$, probably due to the difficulty in assessing this vascular compartment. Recently, the authors used near-infrared spectroscopy (NIRS), a technology widely used for the in vivo evaluation of tissue oxygenation and blood flow, to measure microvascular bed volume (MBV) partitioning in $\mathrm{Vu}$ and $\mathrm{Vs}$, and pressures therein, in humans. ${ }^{17}$ unchanged. Fluid balance correlated with Pit $(r=0.83$, $p<0.001)$ and hemoglobin $(r=0.78, p=0.004)$. A nonlinear regression was found between fluid balance and $\Delta \mathrm{Vu}(\mathbf{r}=$ $0.90, p<0.001)\left[y=1.85+37.43^{(-0.01 \times x)}\right]$. The Vu/Pit and Vs/Ps ratios were lower than those of the control patients. Blood flow correlated to Vs/Ps $(r=0.75, p<0.001)$. The time constant was lower than reference $(p=0.005)$ and increased 10 times after CPB.

Conclusions: Cardiac surgery patients have a limited blood volume reserve for venous return due to a reduced microvascular bed capacitance. This study demonstrated that during CPB a positive fluid balance induced an extravascular pressure increase and further reduced blood volume reserve.

(c) 2016 Elsevier Inc. All rights reserved.

KEY WORDS: skeletal muscle, venous compartment, nearinfrared spectroscopy, microvascular bed, cardiopulmonary bypass, valvular disease

This noninvasive, observational study of cardiac surgery patients with valvular diseases and cardiac dysfunction was designed to extend the knowledge of microvascular changes affecting the blood volume reserve for venous return and cardiac load ${ }^{18}$ during off-pump surgery and to evaluate the effects of $\mathrm{CPB}$ on microvascular bed volume partitioning and tissue blood flow (tBF).

The results of this study may help clinicians to assess the determinants of perioperative cardiovascular functional capacity and factors contributing to organ dysfunction. In addition to measurement of the MBV partitioning in $\mathrm{Vs}$ and $\mathrm{Vu}$ skeletal muscle and pressures therein, the authors examined pressure in the $\mathrm{Vu}$ (threshold pressure: Pit, pressure equals extravascular pressure) as an expression of interstitial fluid leakage. The authors also measured the elastic compliance (mvec) and microvascular blood flow. In addition, the possible relationships between microvascular and systemic variables, such as the systemic arterial and venous pressures, and $\mathrm{CO}$ or pump flow were assessed.

From the *Intensive Care Unit, Department of Medical and Surgical Science and Translational Medicine, Faculty of Medicine and Psychology, University of Rome "Sapienza," Roma, Italy; and †Intensive Care Unit, Department of Health Science, University of Florence, University Hospital Careggi, Florence, Italy.

Address reprint requests to Roberto A. De Blasi, MD, Intensive Care Unit, Department of Medical and Surgical Science and Translational Medicine, Faculty of Medicine and Psychology, University of Rome "Sapienza," Via di Grottarossa 1035, 00189 Roma, Italy. E-mail: radbl@libero.it

(C) 2016 Elsevier Inc. All rights reserved.

1053-0770/2601-0001\$36.00/0

http://dx.doi.org/10.1053/j.jvca.2016.06.001 


\section{METHODS}

\section{Patient Population}

This observational, prospective study was conducted at the Cardiovascular Unit of Careggi Hospital, Florence, Italy, an academic center, from June to October 2013. The authors enrolled 20 adult patients with primary valvular disease scheduled for elective surgery with nonpulsatile CPB for a single or combined valve repair/replacement with or without concomitant coronary artery bypass grafting. The surgical risk in each patient was assessed using the EuroSCORE II model. ${ }^{19}$ Patients requiring emergency cardiac procedures or needing axillary or femoral arterial cannulation were excluded. Patients also were excluded for the following criteria: age $<18$ years, pregnant patients and those with cirrhosis, left ventricular ejection fraction $<0.25$, advanced chronic obstructive pulmonary disease, severe arterial hypertension, and a body mass index $>29.9$.

The institutional review board approved the study procedures (M/CE/04 rev13), and each patient gave written, informed consent before inclusion. Data collected from a group of 20 healthy patients, 8 women and 12 men (average age $47.9 \pm 10.5$ years), who participated in a previous study, ${ }^{20}$ were used as reference values (unpublished data). These patients, whose physical status was considered to be American Society of Anesthesiologists class I, underwent general anesthesia for elective maxillofacial surgery and did not experience disorders likely to influence the microcirculation (eg, diabetes, peripheral vascular disease, or chronic venous insufficiency). Anesthesia was induced with $2 \mathrm{mg} / \mathrm{kg}$ of propofol, a bolus injection of $1 \mu \mathrm{g} / \mathrm{kg}$ of remifentanil, and vecuronium bromide, $0.9 \mathrm{mg} / \mathrm{kg}$, and was maintained with a continuous infusion of $4.5 \mathrm{mg} / \mathrm{kg} / \mathrm{hour}$ of propofol, $0.3 \mu \mathrm{g} / \mathrm{kg} / \mathrm{min}$ of remifentanil, and rocuronium, $0.3 \mathrm{mg} / \mathrm{kg} / \mathrm{min}$. The hemoglobin $(\mathrm{Hb})$ value did not reach lower than $13.0 \mathrm{~g} / 100 \mathrm{~mL}$ in control patients. Data were collected 30 minutes after tracheal intubation and mechanical ventilation.

\section{General Management}

After patient placement on the operating table, a pneumatic cuff was placed around the arm, $5 \mathrm{~cm}$ proximal to the antecubital crease, and was connected to an automatic inflation system (Hokanson Rapid Cuff Inflator and AG101 Air Source; PMS Instruments Ltd, Maidenhead, UK) capable of reaching a predefined cuff pressure (Pcuff) in $<0.5$ seconds. A NIRS probe was positioned on the ventral surface of the brachioradial muscle. To avoid differences in hydrostatic pressure requiring a correction factor, the arm cuff and NIRS probe were kept at the same level by placing the patient's forearm in a plastic frame and keeping the arm and elbow at an angle of $135^{\circ}$ at heart level.

\section{Time Points for Data Collection}

Data on systemic cardiovascular and microcirculatory variables were collected 20 minutes after anesthesia induction (pre-CPB), 20 minutes after CPB started (CPB), 20 minutes after separation from $\mathrm{CPB}$ (post-CPB), and 1 hour after admission to the postoperative intensive care unit (ICU). In the control group, data were collected 20 minutes before the end of surgery.

\section{Anesthesia and Perioperative Management}

After premedication with oral benzodiazepine (diazepam, $5 \mathrm{mg}$ ) and intramuscular atropine, $0.5 \mathrm{mg}$ approximately 30 minutes before surgery, all patients underwent continuous electrocardiogram monitoring plus pulse oximetry and invasive arterial pressure monitoring. Anesthesia induction was achieved with sufentanil, 0.5 to $1 \mu \mathrm{g} / \mathrm{kg}$, midazolam, $0.1 \mathrm{mg} / \mathrm{kg}$, and rocuronium, $0.6 \mathrm{mg} / \mathrm{kg}$, and was maintained with propofol, 2.5 to $4 \mathrm{mg} / \mathrm{kg} / \mathrm{hour}$, remifentanil, 0.2 to $0.4 \mu \mathrm{g} / \mathrm{kg} / \mathrm{min}$, and rocuronium, $0.3 \mu \mathrm{g} / \mathrm{kg} / \mathrm{min}$. Excluding $\mathrm{CPB}$, mechanical ventilation was performed with a volume-controlled mode of $50 \%$ oxygen in air using a semiopen circle system. Tidal volume was set at $8 \mathrm{~mL} / \mathrm{kg}$ (ideal body weight) with a positive end-expiratory pressure of $5 \mathrm{cmH}_{2} \mathrm{O}$, and the ventilatory rate was adjusted to keep the partial pressure of arterial carbon dioxide between 35 and $40 \mathrm{mmHg}$.

After induction, an arterial catheter was inserted into the radial artery and a triple-lumen central venous catheter was inserted into the internal jugular vein (echo-guided procedure), connected via standard low-compliant tubing to disposable pressure transducers for arterial pressure and central venous pressure monitoring. Patients received an intravenous injection of $300 \mathrm{U} / \mathrm{kg}$ of porcine heparin before CPB and underwent aortic cannulation to obtain a target kaolin-activated coagulation time (ACT) of 400 seconds. Additional doses of 5,000 $\mathrm{U}$ of heparin were administered at ACT $<300$ seconds and 2,500 $\mathrm{U}$ at ACT $<400$ seconds. CPB pump flow was set at $2.4 \mathrm{~L} / \mathrm{min} / \mathrm{m}^{2}$.

After the start of $\mathrm{CPB}$ and when ventilation was stopped, the body temperature was allowed to decrease to $34^{\circ} \mathrm{C}$ (mild hypothermia) using a heat exchanger. When surgery ended, patients were rewarmed actively and slowly to approximately $37^{\circ} \mathrm{C}$ with warm forced-air convection, and the spontaneous heartbeat was resumed with or without electrical defibrillation. Cardiac function was evaluated using transesophageal echocardiography before and during weaning from CPB. Stroke volume (SV) was calculated by measuring the cross-sectional area and the diameter (d) of the left ventricular outflow tract (LVOT) from the midesophageal long-axis view (LVOT crosssectional area $\left.=\left[\mathrm{d}_{\mathrm{LVOT}} / 2\right]^{2} \times \pi\right)$, and the integral of velocity time (VTI) was measured at the same site $\left(\mathrm{VTI}_{\mathrm{LVOT}}\right)$ with the pulsedwave Doppler at the deep transgastric view: $\mathrm{SV}(\mathrm{mL})=\left[\left(\mathrm{d}_{\mathrm{LVOT}} /\right.\right.$ $\left.2)^{2} \times \pi\right] \times\left(\mathrm{VTI}_{\mathrm{LVOT}}\right)$. CO was derived as the product of the average SV in 5 consecutive beats and the heart rate. Inotropicvasoactive drugs were given according to a protocol-based approach that considered the echocardiographic evaluation of heart function and the mean blood pressure value. Allogeneic packed red blood cell (RBC) transfusions were considered on the basis of oxygen delivery and a hematocrit value $<20 \%$. $^{21}$

After weaning the patient from $\mathrm{CPB}, 0.6$-to- $1 \mathrm{mg}$ of protamine hydrochloride was administered to neutralize the heparin previously administered; this dose is considered adequate if the postprotamine ACT value is within $10 \%$ of the preheparin value. After surgery, all patients were moved while under sedation with propofol $(1 \mathrm{mg} / \mathrm{kg} / \mathrm{h})$ and remifentanil $(0.1 \mu \mathrm{g} / \mathrm{kg} /$ min) to a cardiac surgery ICU, where they reached complete rewarming and hemodynamic and coagulation stability. 


\section{NIRS and Calculation of Variables}

The authors measured the absolute tissue oxyhemoglobin/ myoglobin $\left(\left[\mathrm{HbO}_{2} / \mathrm{MbO}_{2}\right]\right)$ and deoxyhemoglobin/myoglobin ([HHb/HMb]) concentrations in $\mu \mathrm{M}$ in the brachioradial muscle with a continuous-wave quantitative photometer using 4 different wavelengths and 5 laser diode sources (NIMO-4; Nirox Srl, Borgosatotollo, Italy). ${ }^{22}$ Data were acquired at a sampling speed of 1 second, thus yielding adequate data to analyze rapid changes in the tissue $\mathrm{Hb}$ concentration.

When examining the microvascular bed, the authors focused mainly on the total $\mathrm{Hb}$ tissue concentration contained in venules, small veins, and, to a lesser extent, capillaries, because the $\mathrm{Hb}$ contained in the arterial vessels accounts for only $3 \%$ of the whole $\mathrm{Hb}$ measured with NIRS. ${ }^{23}$ The MBV (in milliliters per $100 \mathrm{~mL}$ of tissue) was derived from the $\mathrm{Hb}$ concentration $(\mathrm{g} / \mathrm{dL})^{17}$ in blood samples drawn from each patient, taking into account that $\mathrm{Hb}$ molecular weight equals 64,500 Da. Because tissue $\mathrm{Mb}$ at rest is almost fully oxygenated, ${ }^{24}$ it is widely accepted that light absorption measured using NIRS is derived from $[\mathrm{HHb}]$ and from oxygenated $\mathrm{Hb}$ and $\mathrm{Mb}^{23-25}$

To obtain the microvascular volume and pressure variables (Vu, Vs, Pit, Ps), the authors applied the same method of cuff venous occlusions used for strain-gauge plethysmography. ${ }^{26-28}$ Using NIRS, changes in the MBV were measured during cumulative 45-second-to-1-minute steps of Pcuff, increasing from $5 \mathrm{mmHg}$ to $10,15,20,30,40$, and $50 \mathrm{mmHg} .{ }^{17}$ Previous studies have demonstrated a close correlation between Pcuff and pressure in veins. ${ }^{29}$ The authors of the study presented here limited Pcuff to a value $10 \mathrm{mmHg}$ lower than the individual patient's diastolic pressure, thus affecting veins rather than arteries. ${ }^{6}$ Because the $\mathrm{Mb}$ concentration in tissue remained constant, the authors attributed changes in light absorption during venous occlusions to only $\left[\mathrm{HbO}_{2}\right]$ and $[\mathrm{HHb}]$.

$\mathrm{Vs}(\mathrm{mL} / 100 \mathrm{~mL}$ of tissue) was measured by subtracting to the MBV, measured before venous occlusions by the absolute tissue $\mathrm{HbO}_{2} / \mathrm{MbO}_{2}$ and the $\mathrm{HHb}$ concentrations, the blood volume resulting from the extrapolation on the pressure axis of the first 2 changes in the MBV after repetitive Pcuff increases. $\mathrm{Vu}(\mathrm{mL} / 100 \mathrm{~mL}$ of tissue) was calculated by subtracting to the $\mathrm{MBV}$, measured before venous occlusions, the $\mathrm{Vs}$ and the $\left[\mathrm{MbO}_{2}\right]$, considered as $40 \%$ of the NIRS signal due to $\left[\mathrm{HbO}_{2} /\right.$ $\mathrm{MbO}_{2}$ ], as previously described. ${ }^{17}$ To calculate pressure in the MBV (PV), before cuff occlusions, the authors considered Pcuff at the first MBV increase, the sum of this blood volume increase, and baseline MBV, thus deriving pressure by proportion. Pit, pressure in the $\mathrm{Vu}$ at which intravascular pressure equals extravascular pressure (transmural pressure $=0$ ), was measured by extrapolating linear regression of the first $2 \mathrm{MBV}$ increases after the steps of Pcuff increase. ${ }^{26}$ The authors considered Pit as the intercept on the pressure axis (x-axis), an independent variable, of the $\triangle \mathrm{MBV}$ (y-axis), a dependent variable, when its value was 0 (Fig 1). The authors calculated pressure in the Vs (Ps) as the difference between PV and Pit.

Because the microvascular bed enlarges differently depending on the intravascular pressure values (see Fig 1), the term "capacitance" was used to refer to the ratio between blood volume changes at distending pressures lower than $30 \mathrm{mmHg}$

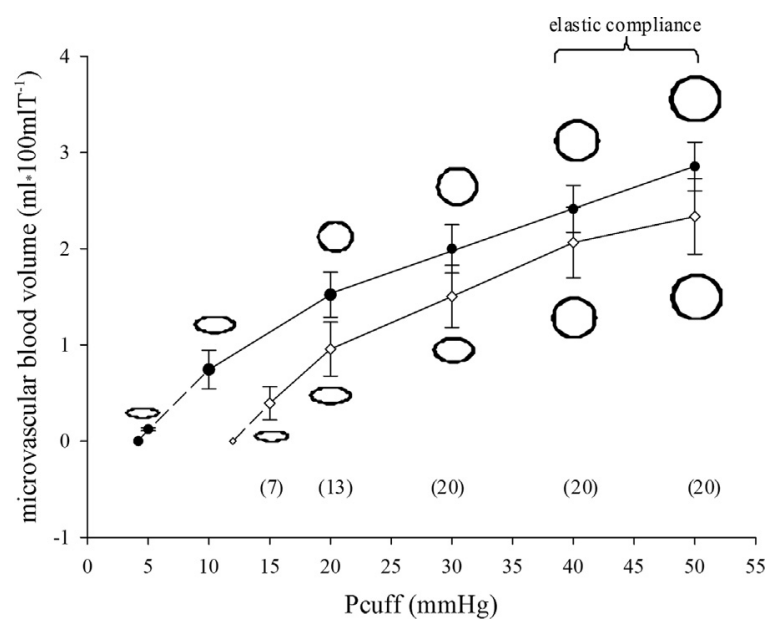

Fig 1. Microvascular blood volume changes measured with NIRS at various cuff pressures in healthy patients (black dots) and cardiac surgery patients with valvular diseases before cardiopulmonary bypass (white dots). Numbers in brackets represent the data measured at each cuff pressure. Cardiac surgery patients showed a higher threshold pressure (Pit: corresponding to the first unstressed volume data measured using NIRS) than that of healthy patients. Microvascular blood volume increase changes its linearity at a cuff pressure lower than $18 \mathrm{mmHg}$ in healthy patients and $40 \mathrm{mmHg}$ cardiac surgery patients. Based on the linearity of blood volume increase, the vascular shape is sketched.

(reflecting mainly the vascular bed recruitment) ${ }^{17,30}$; the term microvascular "elastic compliance" (mvec) was used to refer to blood volume changes at distending pressures greater than $30 \mathrm{mmHg}$ (reflecting the elastic properties of the vascular wall). ${ }^{31}$ The following new NIRS variables were introduced: the capacitance of $\mathrm{Vu}$ or Vs, calculated by the ratios between these volumes and their respective pressures ( $\mathrm{Vu} / \mathrm{Pit}, \mathrm{Vs} / \mathrm{Ps})$, and the time constant $(\tau)$, calculated by dividing the Vs by the $\mathrm{tBF}$, as reported by Magder. ${ }^{32}$ The mvec was measured by calculating the linear regression of $\triangle \mathrm{MBV}$ in the range of 30-to- $50 \mathrm{mmHg}$ Pcuff. Values were expressed as $\mathrm{mL}$ per $\mathrm{mmHg}$ in $100 \mathrm{~mL}$ of tissue, as previously reported. ${ }^{17,33,34}$ The $\mathrm{tBF}$, in milliliters per $100 \mathrm{~mL}$ of tissue per minute, was calculated from the increase in $\left[\mathrm{HbO}_{2}\right]$ during the first 20 seconds of venous occlusion at $30 \mathrm{mmHg}$ Pcuff, as described elsewhere. ${ }^{35,36}$ Methods and formulas for calculating microvascular volume variables (MBV, Vu, and Vs) and pressures in the MBV (PV), in the Vu (threshold pressure: Pit, equal to pressure outside vessels), and in the Vs (Ps, corresponding to mean circulatory pressure) are reported with the methods for calculating mvec and $\mathrm{tBF}$ in the supplemental material for this article.

To assess the effect of fluid loading on microvascular variables during $\mathrm{CBP}$, the authors calculated the balance of fluids infused or added to circuits and lost or subtracted during CPB between pre-CPB and post-CPB measurements.

\section{Statistical Analysis}

Based on prior data, the authors calculated that a sample size of 20 patients would detect a difference in the variable means as low as \pm 0.78 , with a probability power higher than $80 \%$ and an alpha error $<0.05$ (PS Size Calculations software, 
version 3.0; Informer Technologies). The KolmogorovSmirnov test was used to assess normal data distribution. A one-way analysis of variance for repeated measurements was used to test differences among values if normally distributed; otherwise, the data were analyzed using the Wilcoxon signedrank test. For between-group comparisons, the $t$-test was used for paired data normally distributed; otherwise, the MannWhitney $U$-test was used. Correlations among variables were tested with Pearson's correlation test for normally distributed values or Spearman's test, and single or multiple regression analysis was used to determine possible correlations among variables. The relationship among variables was tested with linear or nonlinear regressions. All data were expressed as mean \pm standard deviation or median $25 \%$ to $75 \%$ interquartile range, and $\mathrm{p}$ values $<0.05$ were considered statistically significant. Data were analyzed with Systat Software, Version 12.0 (Systat Software Inc, San Jose, CA).

\section{RESULTS}

All 20 patients enrolled completed the study, and their airways were extubated within 8 hours of the end of surgery (median 6, range 3.30-7.40 hours). Patients' age ranged from 49 to 88 years, and $60 \%$ were male. Most of the patients had a medium or high cardiac surgical risk, and only $10 \%$ had a low risk (Table 1). Norepinephrine (NE) and epinephrine were administered to all patients only after $\mathrm{CPB}$ discontinuation and in the ICU. NE was administered in 14 patients (70\%), with doses ranging from 0.04 to $0.20 \mu \mathrm{g} / \mathrm{kg}^{\prime} \min$ (mean $0.13 \pm 0.11$ $\mu \mathrm{g} / \mathrm{kg}^{\prime} \mathrm{min}$ ), and epinephrine was added to $\mathrm{NE}$ in 8 patients (mean $0.07 \pm 0.09 \mu \mathrm{g} / \mathrm{kg} / \mathrm{min}$ ). None of the patients required nitroglycerine or other vasodilator drugs. The mean duration of $\mathrm{CPB}$ was $116.1 \pm 34.9$ minutes and ranged from 50 to 175 minutes. As expected, the hematocrit decreased during and soon after $\mathrm{CPB}$ and returned to pre-CPB values in the ICU. Eight patients received allogeneic packed RBC transfusions (40\%) ranging from 200 to $600 \mathrm{~mL}$ (median $450 \mathrm{~mL}$, interquartile range $350-600 \mathrm{~mL}$ ). The fluid balance during $\mathrm{CPB}$ was positive in all patients and ranged from 100 to 1,690 $\mathrm{mL}$ (Table 2).

\section{Systemic Cardiocirculatory, Temperature, and Metabolic Variables}

Among the systemic variables measured during cardiac surgery, the systolic pressure after CPB was lower than that measured before $\mathrm{CPB}$, whereas diastolic pressure was unchanged. Mean and systolic arterial pressures measured in the ICU matched pre-CPB values and were higher than those measured after CPB. In contrast, diastolic pressure in the ICU was lower than that before $\mathrm{CPB}$ (see Table 2). The $\mathrm{CO}$ values before CPB matched those of pump flow and decreased by $12 \%$ soon after $\mathrm{CPB}$ and then reverted to initial values in the ICU. SV showed the same trend as CO, decreasing by $33 \%$ after $\mathrm{CPB}$ and then reverting to pre-CPB values in the ICU. Central venous pressure was unchanged during surgery but decreased in the ICU. As expected, temperature decreased by a mean of $22 \%$ during CPB (range from $14 \%$ to 28\%) and increased when patients were rewarmed. Serum lactate concentration increased during and soon after $\mathrm{CPB}$ by no more
Table 1. Demographic and Anthropometric Data, Surgical Procedures, Cardiac Surgical Risk, and Comorbidities for 20 Patients With Valvular Diseases Undergoing Elective Cardiac Surgery With Nonpulsatile Cardiopulmonary Bypass

\begin{tabular}{lc}
\hline Demographic and anthropometric data & $12 / 8$ \\
Sex, $\mathrm{n}, \mathrm{M} / \mathrm{F}$ & $67.2(4.6)$ \\
Age, mean (SD), years & $25.0(23.5-27.5)$ \\
$\mathrm{BMI}$, median $(\mathrm{IQR}),\left(\mathrm{kg} / \mathrm{m}^{2}\right)$ & \\
Surgical procedures, $\mathrm{n}(\%)$ & $17(85)$ \\
AVR & $5(25)$ \\
MVR & $4(29)$ \\
TVR & $3(15)$ \\
MAZE & $7(35)$ \\
CABG & \\
Valvular diseases, $\mathrm{n}(\%)$ & $15(75)$ \\
Aortic valve stenosis & $4(20)$ \\
Regurgitation & $4(20)$ \\
Mitral valve stenosis & $3(15)$ \\
Regurgitation & $4(20)$ \\
Tricuspid valve regurgitation & $4.6(2.3-9.2)$ \\
EuroSCORE, median (IOR) & $2(10)$ \\
Low risk, $\mathrm{n}$ & $8(40)$ \\
Medium risk, $\mathrm{n}$ & $10(50)$ \\
High risk, $\mathrm{n}$ & \\
Comorbidities, $\mathrm{n}(\%)$ & $9(45.0)$ \\
Myocardial infarction & $15(75.0)$ \\
Hypertension & $12(60.0)$ \\
Hyperlipidemia & $11(55.0)$ \\
Chronic obstructive pulmonary disease & $3(15.0)$ \\
Restrictive pulmonary disease & $5(25.0)$ \\
Diabetes mellitus & $2(10.0)$ \\
Chronic renal failure & $8(40.0)$ \\
Peripheral arterial disease & \\
\hline Abeviations: AVR, aotic vave & \\
\hline
\end{tabular}

Abbreviations: AVR, aortic valve replacement; $\mathrm{BMI}$ body mass index; CABG, coronary artery bypass graft; IQR (25\%-75\%) interquartile range; MAZE, maze procedure for atrial fibrillation; MVR, mitral valve replacement; SD, standard deviation; TVR, tricuspid valve replacement.

than $2.5 \mathrm{mmol} / \mathrm{L}$ and decreased to pre-CPB values in the ICU. $\mathrm{pH}$ was unchanged during surgery and in the ICU, but baseline partial pressure of arterial carbon dioxide values increased after CPB and in the ICU (see Table 2). Blood Hb oxygen saturation was $\geq 97 \%$ at all measurements in all patients.

\section{Microvascular Volume and Pressure Variables}

The MBV and $\mathrm{Vu}$ values before CPB matched reference values but increased after the onset of $\mathrm{CPB}$, doubling their values at off-pump measurement. In contrast, Vs measured before $\mathrm{CPB}$ showed values half that of the reference, which increased at the on- and off-pump measurements. The MBV, $\mathrm{Vu}$, and $\mathrm{Vs}$ values recovered in the ICU and matched the values measured before CPB (Table 3). The MBV changes during the study were related strictly to changes in $\mathrm{Vu}(r=$ $0.99, \mathrm{p}<0.001)$ and to a lesser extent to Vs $(r=0.45, \mathrm{p}=$ 0.004).

The PV and Pit values measured before CPB were more than twice those of the reference values, whereas the Ps values matched those of the reference values. Tests performed to evaluate perioperative changes in pressure variables showed an increase in the Ps values after CPB discontinuation but no 
Table 2. Hemodynamic and Metabolic Variables, Vasoactive Medications, and Fluid Balance

\begin{tabular}{|c|c|c|c|c|c|c|}
\hline Variables & Pre-CPB & $\mathrm{CPB}$ & Post-CPB & $\mathrm{p}$ Value & $\mathrm{ICU}$ & $\begin{array}{l}\text { ICU vs Pre-CPB, CPB, } \\
\text { Post-CPB (p Value) }\end{array}$ \\
\hline Mean arterial pressure, $\mathrm{mmHg}$ & $77.6(11.6)$ & $72.6(12.5)$ & $* 67.2(9.2)$ & 0.027 & $78.8(14.5)$ & $0.834,0.298,0.032$ \\
\hline Systolic pressure, $\mathrm{mmHg}$ & $113.5(14.2)$ & - & ${ }^{*} 98.2(20.1)$ & 0.029 & $118.9(19.2)$ & $0.489,0.034$ \\
\hline Diastolic pressure, $\mathrm{mmHg}$ & $68.2(10.1)$ & - & $60.75(11.6)$ & 0.102 & $56.7(12.2)$ & $0.038,0.482$ \\
\hline Heart rate, beats/min & $66.1(14.0)$ & - & $86.8(11.6)$ & $<0.001$ & $76.3(8.9)$ & $0.036,0.016$ \\
\hline Cardiac output or pump flow (L/min) & $4.01(0.34)$ & $4.27(0.78)$ & $*+3.54(0.48)$ & 0.004 & $4.35(0.45)$ & $0.039,0.752,<0.001$ \\
\hline Stroke volume, $\mathrm{mL}$ & $63.5(13.3)$ & - & $42.6(7.8)$ & $<0.001$ & $54(8.4)$ & $0.076,0.048$ \\
\hline Central venous pressure, $\mathrm{mmHg}$ & $9.2(4.7)$ & $10.4(3.8)$ & $9.5(5.6)$ & 0.076 & $7.3(3.5)$ & $0.038,0.024,0.034$ \\
\hline Temperature, $\mathrm{C}$ & $36.3(0.6)$ & $\mp 28.4(3.3)$ & $* 30.2(0.3)$ & 0.003 & $35.9(2.2)$ & $0.738,0.012,0.045$ \\
\hline Hct, \% & $37.9(4.1)$ & $\neq 27.4(3.5)$ & ${ }^{*}+28.6(4.6)$ & $<0.001$ & $35.3(4.3)$ & $0.168,<0.001,0.003$ \\
\hline $\mathrm{pH}$ & $7.43(0.03)$ & $7.43(0.08)$ & $7.41(0.07)$ & 0.087 & $7.40(0.04)$ & $0.387,0.343,0.876$ \\
\hline $\mathrm{pCO}_{2}, \mathrm{mmHg}$ & $34.5(3.5)$ & $37.4(5.6)$ & *40.4 (3.9) & 0.003 & $43.2(4.2)$ & $0.003,0.023,0.089$ \\
\hline Lactates, $\mathrm{mmol} / \mathrm{L}$ & $1.03(0.20)$ & ${ }^{c} 2.11(0.37)$ & *1.60 (0.44) & 0.002 & $1.47(0.34)$ & $0.038,0.022,0.342$ \\
\hline \multicolumn{7}{|l|}{ Vasoactive drugs, $\mu \mathrm{g} / \mathrm{kg} / \mathrm{min}$} \\
\hline Norepinephrine, $\mathrm{n}$ (dose range) & - & - & \multicolumn{2}{|c|}{$14(0.03-0.20)$} & $3(0.03-0.15)$ & \\
\hline Epinephrine $\mathrm{n}$ (dose range) & - & - & \multicolumn{2}{|c|}{$8(0.05-0.1)$} & - & \\
\hline Fluid balance, $\mathrm{mL}$ & - & - & \multicolumn{2}{|c|}{$874.7(445.0)$} & & \\
\hline
\end{tabular}

NOTE. Results are presented as values of variables before cardiopulmonary bypass (pre-CPB), 20 minutes after CPB started (CPB), 20 minutes after CPB recovery (post-CPB), and 1 hour after postoperative intensive care unit admission.

Abbreviations: Hct, hematocrit; $\mathrm{pCO}_{2}$, partial pressure of carbon dioxide.

Bonferroni's test was used for post-hoc comparison among variables. Mean arterial pressure: ${ }^{*} p=0.036$ versus pre-CPB; systolic pressure: ${ }^{*} p=0.010$ versus pre-CPB; cardiac output: ${ }^{*} p=0.031$ versus pre-CPB, $\uparrow p=0.004$ versus $C P B$; temperature: $\neq p=0.002,{ }^{*} p=0.012$ versus pre$\mathrm{CPB}, \mathrm{Hct:}{ }^{*} \neq \mathrm{p}<0.001$ versus pre-CPB; $\uparrow \mathrm{p}=0.032$ vs $\mathrm{CPB} ; \mathrm{pCO}_{2}:{ }^{*} \mathrm{p}<0.001$ versus pre-CPB; lactates: $\ddagger \mathrm{p}=0.012,{ }^{*} \mathrm{p}=0.034$ versus pre-CPB.

significant changes in Pit values. In the ICU, pressure variables matched those measured before CPB (see Table 3). No difference was found in volume-pressure variables when patients treated or untreated with vasoactive drugs were compared.

Correlation tests showed a positive correlation between net fluid balance and absolute Pit values $(r=0.83, \mathrm{p}<0.001)$ and blood $\mathrm{Hb}$ concentration measured after CPB $(r=0.78, \mathrm{p}=$ 0.004). When testing the relationship between the balance of fluids given to patients during $\mathrm{CPB}$, as an independent variable, and the CPB-induced changes in microvascular volume variables, a nonlinear regression was found between fluid balance and $\Delta \mathrm{Vu}(r=0.90, \mathrm{p}<0.001)$ (Fig 2). Therefore, with a greater positive balance, the lower $\mathrm{Vu}$ change was measured with an exponential decay described by the following equation: $\mathrm{y}=1.85+37.43^{(-0.01 \times \mathrm{x})}$. In contrast, no correlation was found between the microvascular variables and the duration of CPB.

\section{Microvascular Capacitance, Compliance, and Blood Flow}

The mvec values measured before CPB matched those of the reference values and were unchanged during the study. In contrast, the microvascular bed capacitance (Vu/Pit and Vs/Ps ratios) before $\mathrm{CPB}$ was lower than that of the reference values, and CPB yielded a wide variability in volume/pressure ratios with no statistical significance (Fig 3). In the ICU, tests showed that Vs/Ps values were lower than those measured soon after CPB.

The $\mathrm{tBF}$ values measured before $\mathrm{CPB}$ matched reference values and remained statistically unchanged during the study but decreased in the ICU. Although the blood flow remained statistically unchanged during cardiac surgery, multiple linear regression analysis performed to assess the relationship between $\mathrm{tBF}$, as a dependent variable, and microvascular volume or pressure showed that $\mathrm{tBF}$ was correlated weakly with Vs $(r=0.59, \mathrm{p}=0.032)$ and to a higher degree with $\mathrm{Vs} /$ Ps $(r=0.75, \mathrm{p}<0.001)$. The $\tau$ of the vascular bed contributing to perfusion (Vs) showed lower values (faster flow) than the reference values $(p=0.005)$ and increased (slower flow) approximately 10 -fold after CPB discontinuation (Fig 4). No correlation between $\tau$ and Hct values was observed. No differences in the volume/pressure ratio, mvec, or tBF were observed between patients who did or did not receive vasoactive drugs after CPB and in the ICU.

Correlation tests showed no relationship between the microvascular volume or pressure variables and arterial pressure or cardiac or pump flow.

\section{DISCUSSION}

This noninvasive, observational study showed that, as hypothesized, patients with valvular diseases and a medium or high cardiac surgical risk have altered skeletal muscle microvascular bed partitioning and pressures therein-the Vs was smaller and pressure in the $\mathrm{Vu}$ was greater than in healthy patients. The study presented here also showed that CPB enlarged microvascular $\mathrm{Vs}$ and $\mathrm{Vu}$ and increased pressure inside the $\mathrm{Vs}$ without changes in the microvascular elastic compliance or the overall blood flow. In addition, fluid overload increased pressure in the extravascular space and reduced the reserve of blood available to maintain filling pressure in the right heart. Finally, although the overall results showed no correlation between microvascular and macrovascular variables, the decreases in post-CPB $\mathrm{CO}$ and arterial pressure could have altered MBVs and pressures.

These results highlighted a reduced capacitance of the overall venous compartment of the microvascular bed, as evidenced by the lower volume/pressure ratios compared with healthy patients. However, Vs and Vu demonstrated opposite findings. Despite an inside driving pressure in the normal 
Table 3. Microvascular Variables

\begin{tabular}{|c|c|c|c|c|c|c|c|c|}
\hline & \multicolumn{6}{|c|}{ Cardiac Surgery Patients (20) } & \multirow[b]{2}{*}{$\begin{array}{l}\text { Reference Control } \\
\text { Patients (20) }\end{array}$} & \multirow{2}{*}{$\begin{array}{c}\begin{array}{c}\text { Pre-CPB Versus } \\
\text { Reference }\end{array} \\
\text { p Value }\end{array}$} \\
\hline & pre-CPB & $\mathrm{CPB}$ & post-CPB & $\mathrm{p}$ Value & $\mathrm{ICU}$ & $\begin{array}{c}\text { ICU Versus pre-CPB to } \\
\text { post-CPB p Value }\end{array}$ & & \\
\hline \multicolumn{9}{|l|}{ Microvascular volume variables } \\
\hline MBV, $\mathrm{mL} / 100 \mathrm{~mL}$ tissue & $3.34(0.94)$ & *5.35 (1.83) & †6.80 (4.40) & 0.002 & $3.35(2.30)$ & $0.990-\ddagger 0.009$ & $3.44(0.74)$ & 0.818 \\
\hline $\mathrm{Vu}, \mathrm{mL} / 100 \mathrm{~mL}$ tissue & $3.16(1.02)$ & *5.06 (1.68) & t6.37 (4.29) & 0.004 & $3.22(2.27)$ & $0.932-\ddagger 0.017$ & $3.06(0.66)$ & 0.806 \\
\hline $\mathrm{Vs}, \mathrm{mL} / 100 \mathrm{~mL}$ tissue & $0.19(0.29)$ & $* 0.29(0.25)$ & & 0.032 & $0.13(0.07)$ & 0.525 to $\ddagger<0.001$ & $0.38(0.18)$ & $\mp 0.027$ \\
\hline \multicolumn{9}{|l|}{ Microvascular pressure variables } \\
\hline $\mathrm{PV}, \mathrm{mmHg}$ & $16.56(6.95)$ & $15.60(6.68)$ & $t^{\S} 22.81(10.56)$ & $<0.001$ & $15.72(9.04)$ & $0.789-0.122$ & $7.32(3.67)$ & ${ }^{\dagger} 0.002$ \\
\hline Pit, mmHg & $11.96(8.00)$ & $9.97(6.22)$ & $14.51(8.33)$ & 0.082 & $10.84(8.68)$ & $0.759-0.339$ & $4.87(4.41)$ & $\neq 0.034$ \\
\hline Ps, $\mathrm{mmHg}$ & $4.60(5.26)$ & $5.64(5.18)$ & $\neq 8.82(5.44)$ & 0.045 & $4.88(4.43)$ & $0.423-0.045$ & $2.45(2.32)$ & 0.405 \\
\hline \multicolumn{9}{|c|}{$\begin{array}{l}\text { Microvascular compliance, capacitance, and } \\
\text { blood flow }\end{array}$} \\
\hline mvec, $\mathrm{mL} / \mathrm{mmHg} \times 100 \mathrm{~mL}$ of tissue & $0.041(0.019)$ & $0.042(0.024)$ & $0.055(0.043)$ & 0.174 & $0.035(0.022)$ & $0.423-0.166$ & $0.056(0.039)$ & 0.310 \\
\hline $\mathrm{Vu} / \mathrm{Pit}, \mathrm{mL} / \mathrm{mmHg}$ & $0.21(0.25)$ & $0.34(0.64)$ & $0.64(2.43)$ & 0.783 & $0.32(0.96)$ & $0.089-0.086$ & $0.38(0.75)$ & $\ddagger 0.019$ \\
\hline $\mathrm{Vs} / \mathrm{Ps}, \mathrm{mL} / \mathrm{mmHg}$ & $0.07(0.07)$ & $0.15(0.29)$ & $0.08(0.03)$ & 0.299 & $0.04(0.02)$ & $0.271-0.049$ & $0.26(0.22)$ & $\ddagger 0.015$ \\
\hline $\mathrm{mBF}, \mathrm{mL} / \mathrm{min} / 100 \mathrm{~mL}$ of tissue & $8.64(8.86)$ & $7.85(4.00)$ & $7.96(7.26)$ & 0.908 & $2.65(1.83)$ & $\ddagger 0.028-0.070$ & $6.61(5.69)$ & 0.635 \\
\hline$\tau, \mathrm{mL} / \mathrm{mL} / \mathrm{min} / 100 \mathrm{~mL}$ of tissue & $0.027(0.03)$ & $0.053(0.05)$ & †0.229 (0.38) & 0.048 & $0.092(0.11)$ & $\ddagger 0.012-0.671$ & $0.06(0.03)$ & 0.005 \\
\hline
\end{tabular}

NOTE. Microvascular variables were measured in 20 cardiac surgery patients 20 minutes after anesthesia induction (pre-CPB), 20 minutes after CPB started (CPB), 20 minutes after CPB recovery (post-CPB), and 1 hour after ICU admission. Data measured in healthy patients were used as reference controls. Bonferroni's test was used for post-hoc comparison to identify the following: MBV, microvascular bed volume: ${ }^{*}+p=0.002$ versus pre-CPB; $\mathrm{Vu}$, unstressed volume: $\dagger p<0.001,{ }^{*} p=0.0032$ versus pre-CPB; $V s$, stressed volume: ${ }^{*} p=0.002,+p=0.026$ versus pre-CPB; $\mathrm{PV}$, pressure in the microvascular bed volume: ${ }^{*} p=0.001$ versus pre-CPB, $\$ p<0.001$ versus $C P B$; Ps, pressure in the stressed volume $\dagger p=0.045$ versus pre-CPB; $\tau$, time constant: $\dagger p=0.003$ versus pre-CPB. $\neq \mathrm{p}<0.05$. 


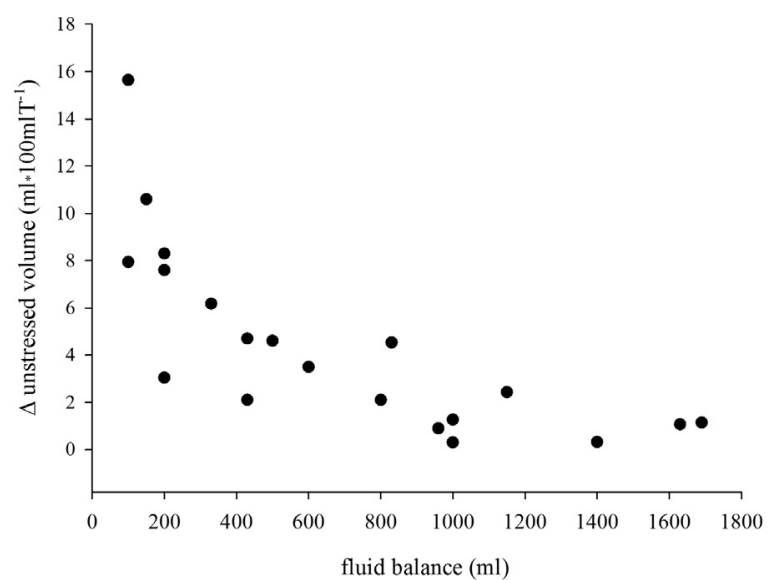

Fig 2. Scatter plots of the unstressed volume changes $(\Delta \mathrm{Vu})$ and balance of fluids (net fluid balance in milliliters from time point before and after cardiopulmonary bypass) in the $\mathbf{2 0}$ cardiac surgery patients during the study. Values are related with an exponential decay described in the equation: $y=1.85+37.43(-0.01 \times x)$ and a regression coefficient $0.90(p<0.001)$, so that the greater the positive balance, the lower $\Delta \mathrm{Vu}$ is measured.

range, the stressed (hemodynamically active) microvascular bed in patients with valvular disease supplied less volume to venous return compared with that of healthy patients; hence, cardiac surgery patients could have a limited blood volume reserve for venous return and $\mathrm{CO}$. Conversely, the unstressed (hemodynamically inactive) vascular bed required pressure values of up to 2.5 times greater than reference values to remain open. Therefore, in those patients, most of the venous pressure was spent preserving the overall microvascular bed volume but not tissue perfusion. Because pressure in the $\mathrm{Vu}$ and Pit equals pressure outside the vessels in the interstitium, the cardiac surgery patients experienced an extravascular pressure higher than that in the healthy patients, probably due to their underlying cardiovascular diseases. In addition, high interstitial pressure, likely caused by an increase in fluids in the extravascular space, is an obstacle to oxygen diffusion from capillaries to cells, thus limiting the chance of tissue oxygenation. Also, as shown by the time constant, a low Vs with a normal blood flow entails a fast transit time for erythrocytes in the microcirculation, which could be detrimental to the ability of cells to extract oxygen for their needs. ${ }^{37}$ The authors found that the reduced capacitance (low volume/pressure ratio) of the microvascular bed, with the elastic properties of the vascular wall unchanged, may reflect a poorly recruited vascular bed.

\section{CPB}

From these results, it appeared that CPB had an effect on the microvascular bed in which volumes and pressures already were altered. The increases in $\mathrm{Vs}$ and $\mathrm{Vu}$, with unchanged volume/pressure ratios and compliance, suggested that recruitment of the vascular bed was the result of factors triggered by the use of CPB itself.

\section{Fluid Balance}

The strong positive correlation between Pit and fluid balance in these patients on CPB suggested that fluid overload

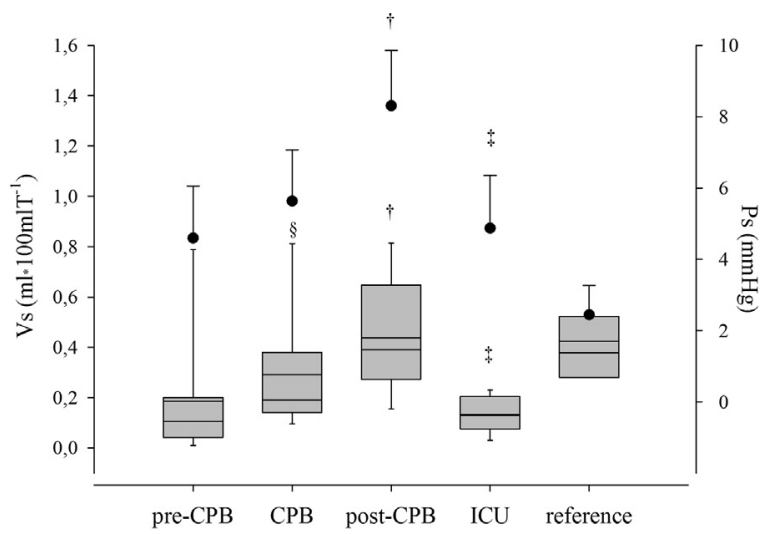

Fig 3. Box plots and scatter plots with standard errors of the stressed volume (Vs) (box plots: mean, median, standard error, and percentiles) and pressure therein (black dots) in the forearm microvascular bed of the $\mathbf{2 0}$ cardiac surgery patients and the $\mathbf{2 0}$ reference healthy control patients. Variables were collected before cardiopulmonary bypass (pre-CPB), 20 minutes after CPB began (CPB), 20 minutes after recovery from CPB (post-CPB), and in the postoperative intensive care unit. §†p $<0.05$ versus pre-CPB; $\neq p<0.05$ versus post-CPB.

increased the interstitial pressure due to capillary leak. The findings of this study confirmed the CPB-induced extravascular fluid leakage demonstrated in adults and children caused by the diffuse inflammatory response that was believed to contribute to postoperative morbidity. ${ }^{38-43} \mathrm{~A}$ rise in the extravascular pressure, due to fluid overload, could explain the smaller the changes in the $\mathrm{Vu}$ the more positive the balance of fluids during CPB.

Despite ample evidence to prove that a variety of inflammatory mediators were involved in the pathogenesis of the systemic inflammatory response during $\mathrm{CPB},{ }^{44}$ the mechanism involved in the capillary leak syndrome still is controversial. ${ }^{45-49}$ Evidence that the protein content in the interstitial space did not increase in children undergoing $\mathrm{CPB}$ suggested that lymphatic

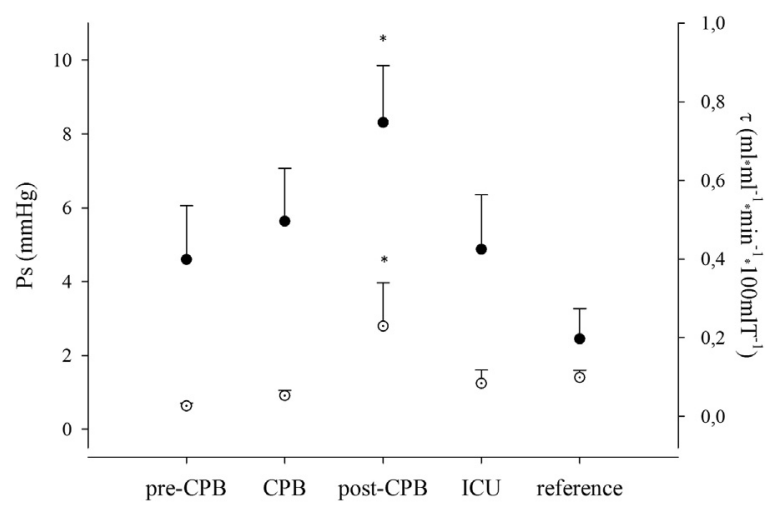

Fig 4. Scatter plots with standard error bars of pressure in stressed volume (Ps) (black dots) and microcirculation time constant $(\tau)$ (white dots) were used to calculate the stressed volume/tissue blood flow rates in the forearm microvascular bed of the $\mathbf{2 0}$ cardiac surgery patients and the 20 reference healthy control patients. Variables were collected before cardiopulmonary bypass (pre-CPB), 20 minutes after CPB began (CPB), 20 minutes after recovery from CPB (post-CPB), and in the postoperative intensive care unit. ${ }^{*} p<0.05$ versus pre-CPB. 
drainage impairment, increased microvascular filtration caused by hypothermia, a decreased glycocalyx thickness, and hemodilution may be causative factors of fluid leakage..$^{40,41,43,50}$ The results of this study, showing a correlation between fluid balance and blood $\mathrm{Hb}$ concentration, proved that hemodilution was involved in CPB-induced fluid leakage.

\section{Tissue Blood Flow}

The "in vivo" results of this study showed that during cardiac surgery, microvascular blood flow in skeletal muscle varied according to the capacitance of the Vs compartment. The increase in Vs with constant blood flow entailed a slower transit time for erythrocytes during and soon after CPB, resulting in an increase in oxygen extraction from cells together with a decrease in blood $\mathrm{Hb}$ concentration.

\section{Vasoactive Drugs}

Because vasoactive drugs were used almost exclusively to wean patients from $\mathrm{CPB}$, the authors hypothesized that in hemodynamically unstable patients the use of these drugs may have contributed to maintaining constant capacitance and compliance of the microvascular bed. Nevertheless, these results showing higher Ps values after CPB discontinuation compared with those measured before and after the onset of CPB suggested a role for endogenous or exogenous vasoactive drugs in reduced Vs capacitance. Reduced Vs capacitance in turn limited the blood flow, as demonstrated by the correlation between Vs/Ps and tBF, and this could be another effect of the vasoactive drugs.

\section{After CPB}

Although mean arterial pressure and CO decreased after CPB discontinuation, they showed no correlation with microvascular variables. This added to the abundant evidence demonstrating the independence of the microcirculation from the macrocirculation $^{51-53}$ within the observed pressure range. Despite the absence of a correlation between $\mathrm{CO}$ and volume or pressure microvascular variables, the decrease in macrovascular variables after CPB weaning probably would exert an effect on the increase in pressure in Vs, which remained enlarged. If the transit time measured before on-pump surgery was faster than that measured in healthy patients, it reduced markedly after CPB.

\section{Intensive Care Unit}

Recovery of microvascular variables in the ICU to the values measured before $\mathrm{CPB}$ may indicate the effects of $\mathrm{CPB}$ on the microcirculation. As previously reported, among the factors affecting the microvascular bed during and immediately after CPB, excess fluids play a preeminent role in impairment of the microvascular bed and tissue perfusion. The removal of fluids using diuretics resulting in a negative fluid balance is probably a determinant in the recovery of variables in the postoperative period.

\section{Limitations}

This study had some limitations. The microvascular bed of skeletal muscles contributed approximately $20 \%$ to the overall blood volume. ${ }^{54}$ This relatively small contribution could have made these results less meaningful. Despite this drawback, according to other authors, ${ }^{55}$ the measurements of Vs and pressure in the forearm could be extended to the microcirculation in other body areas. Another limitation was the possible inaccuracy in estimating Mb concentration. Although the absolute $\mathrm{Mb}$ value may have been inaccurate, the authors considered the measurement of microvascular bed partitioning before venous occlusion to be reliable and regarded any changes in the NIRS signal during the study to be due to $\mathrm{Hb}$ only. A final limitation was the small number of patients studied, although differences measured in small groups often yield useful data for clinical purposes.

\section{Future Studies}

The findings of this study indicated the need to extend the knowledge on other aspects of cardiac surgery, such as the volume of RBC transfusions or the effects of CPB in patients without valvular diseases involving the venous compartment of the microvascular bed. Because these were preliminary results, the effects of changes in the therapeutic strategy (ie, blood volume limitation) require further investigation. Future research also should provide greater insight into cardiac disease progression according to age in a large number of patients.

\section{CONCLUSION}

These results showed that cardiac surgery patients with valvular diseases and a medium or high cardiac surgical risk had a limited blood volume reserve to maintain filling pressure for venous return to the right heart due to highly reduced capacitance in the venous compartment of the microvascular bed. This in vivo study also demonstrated that during CPB, fluid overload, which increased the extravascular pressure, reduced oxygen diffusion to cells and the reserve of blood available for venous return. These findings added to the knowledge on factors that could have injurious effects on organs and tissues during cardiac surgery.

\section{APPENDIX A. SUPPLEMENTARY MATERIAL}

Supplementary data associated with this article can be found in the online version at http://dx.doi.org/10.1053/j.jvca.2016.06.001.

\section{REFERENCES}

1. Brown JR, Cochran RP, Leavitt BJ, et al: Multivariable prediction of renal insufficiency developing after cardiac surgery. Circulation 116: I139-I143, 2007

2. Asimakopoulos G, Smith PL, Ratnatunga CP, et al: Lung injury and acute respiratory distress syndrome after cardiopulmonary bypass. Ann Thorac Surg 68:1107-1115, 1999
3. Parissis H, Mbarushimana S, Ramesh BC, et al: The impact of offpump surgery in end-organ function: Practical end-points. J Cardiothoracic Surgery 10:159-170, 2015

4. Bashore TM: Clinical hemodynamics in valvular heart disease. In Wang A, Bashore TM (eds): Valvular heart disease. New York, Humana Press, 2009, pp 101-102 
5. Abboud FM, Mark AL, Heidstadd DD, et al: The venous system. In Levine H (ed): Cardiovascular pathophysiology. New York, Grune \& Stratton, 1976, pp 207-257

6. Greenway CV, Lister GE: Capacitance effects and blood reservoir function in the splanchnic vascular bed during non-hypotensive haemorrhage and blood volume expansion in anaesthetized cats. J Physiol 237:279-294, 1974

7. Magder S, Scharf SM: Venous return, respiratory-circulatory interactions. In Scharf SM, Pinsky MR, Magder S (eds): Health and disease. New York, Marcel Dekker, 2001, pp 93-112

8. Rothe CF: Mean circulatory filling pressure: Its meaning and measurement. J Appl Physiol 74:499-509, 1993

9. Stamler A, Wang SY, Aguirre DE, et al: Cardiopulmonary bypass alters vasomotor regulation of the skeletal muscle microcirculation. Ann Thorac Surg 64:460-465, 1997

10. Koning NJ, Atasever B, Vonk ABA, et al: Changes in microcirculatory perfusion and oxygenation during on-pump and off-pump cardiac surgery. J Cardiothorac Vasc Anesth 28:1331-1340, 2014

11. Bienz M, Drullinsky D, Stevens LM, et al: Microcirculatory response during on-pump versus off-pump coronary artery bypass graft surgery. Perfusion 31:207-215, 2015

12. De Blasi RA, Tonelli E, Arcioni R, et al: In vivo effects on human skeletal muscle oxygen delivery and metabolism of cardiopulmonary bypass and perioperative hemodilution Intensive Care Med 38: 413-421, 2012

13. Bauer A, Kofler S, Thiel M, et al: Monitoring of the sublingual microcirculation in cardiac surgery using orthogonal polarization spectral imaging. Anesthesiology 107:939-945, 2007

14. Doerschug KC, Delsing AS, Schmidt GA, et al: Impairments in microvascular reactivity are related to organ failure in human sepsis. Am J Physiol Heart Circ Physiol 293:H1065-H1071, 2007

15. den Uil CA, Lagrand WK, Spronk PE, et al: Impaired sublingual microvascular perfusion during surgery with cardiopulmonary bypass: A pilot study. J Thorac Cardiovasc Surg 136:129-134, 2008

16. De Backer D, Dubois MJ, Schmartz D, et al: Microcirculatory alterations in cardiac surgery: Effects of cardiopulmonary bypass and anesthesia. Ann Thorac Surg 88:1396-1403, 2009

17. De Blasi RA, Arcioni R: Assessing skeletal muscle variations in microvascular pressure and unstressed blood volume at the bedside. Microcirculation 21:606-614, 2014

18. Young DB: Control of cardiac output. In Granger DN, Grange JP (eds): Colloquium series on integrated systems physiology: From molecule to function to disease. Rafael, CA, Morgan \& Claypool Life Sciences, 2010

19. Nashef SAM, Roques F, Sharples LD, et al: EuroSCORE II. Eur J Cardiothoracic Surg 41:734-745, 2012

20. De Blasi RA, Palmisani S, Boezi M, et al: Effects of remifentanil-based general anaesthesia with propofol or sevoflurane on muscle microcirculation as assessed by near-infrared spectroscopy Brit J Anaesth 101:171-177, 2008

21. Murphy GJ, Angelini GD: Indications for blood transfusion in cardiac surgery. Ann Thorac Surg 82:2323-2334, 2006

22. Matcher S, Cope M, Delpy D: Use of the water absorption spectrum to quantify tissue chromophore concentration changes in near-infrared spectroscopy. Phys Med Biol 39:177-196, 1994

23. Mancini DM, Bolinger L, Li H, et al: Validation of near-infrared spectroscopy in humans. J Appl Physiol 77:2740-2747, 1994

24. Tran TK, Sailasuta N, Kreutzer U, et al: Comparative analysis of NMR and NIRS measurements of intracellular PO2 in human skeletal muscle. Am J Physiol 276:R1682-R1690, 1999

25. Davis ML, Barstow TJ: Estimated contribution of hemoglobin and myoglobin to near infrared spectroscopy. Respir Physiol Neurobiol 186:180-187, 2013
26. Gamble J, Christ F, Gartside IB: Mercury in silastic strain gauge plethysmography for the clinical assessment of the microcirculation. Postgrad Med J 68:S25-S33, 1992

27. Halliwill JR, Minson CT, Joyner MJ: Measurement of limb venous compliance in humans: Technical considerations and physiological findings. J Appl Physiol 87:1555-1563, 1999

28. Alomari MA, Solomito A, Reyes R, et al: Measurement of vascular function using strain-gauge plethysmography: Technical considerations, standardization and physiological findings. Am J Physiol Heart Circ Physiol 286:H99-H107, 2004

29. Christ F, Gamble J, Baschnegger H, et al: Relationship between venous pressure and tissue volume during venous congestion plethysmography in man. J Physiol 503:463-467, 1997

30. Van Vo T, Hammer PE, Hoimes ML, et al: Mathematical model for the hemodynamic response to venous occlusion measured with near-infrared spectroscopy in the human forearm. IEEE Trans Biomed Eng 54:573-584, 2007

31. Schmitt M, Blackman DJ, Middleton GW, et al: Assessment of venous capacitance. Radionuclide plethysmography: Methodology and research applications. Br J Clin Pharmacol 54:565-576, 2002

32. Madger S: Shock physiology. In Pinsky MR, Vincent JF (eds): Pathophysiologic foundations of critical care. Baltimore, Williams \& Wilkins, 1993, pp 140-160

33. De Blasi RA, Palmisani S, Alampi D, et al: Microvascular dysfunction and skeletal muscle oxygenation assessed by phasemodulation near-infrared spectroscopy in patients with septic shock. Intensive Care Med 31:1661-1668, 2005

34. Binzoni T, Quaresima V, Ferrari M, et al: Human calf microvascular compliance measured by near-infrared spectroscopy. J Appl Physiol 88:369-372, 2000

35. De Blasi RA, Ferrari M, Natali A, et al: Noninvasive measurement of forearm blood flow and oxygen consumption by near-infrared spectroscopy. J Appl Physiol 76:1388-1393, 1994

36. Casavola C, Paunescu LA, Fantini S, et al: Blood flow and oxygen consumption with near-infrared spectroscopy and venous occlusion: Spatial maps and the effect of time and pressure of inflation. J Biomed Opt 5:269-276, 2000

37. Østergaard L, Kristiansen SB, Angleys H, et al: The role of capillary transit time heterogeneity in myocardial oxygenation and ischemic heart disease. Basic Res Cardiol 109:409-427, 2014

38. Hamada Y, Kawachi K, Tsunooka N, et al: Capillary leakage in cardiac surgery with cardiopulmonary bypass. Asian Cardiovasc Thorac Ann 12:193-197, 2004

39. Holmes JHT, Connolly NC, Paull DL, et al: Magnitude of the inflammatory response to cardiopulmonary bypass and its relation to adverse clinical outcomes. Inflamm Res 51:579-586, 2002

40. Tassani P, Schad H, Winkler C, et al: Capillary leak syndrome after cardiopulmonary bypass in elective, uncomplicated coronary artery bypass grafting operations: Does it exist? J Thorac Cardiovasc Surg 123:735-741, 2002

41. Tassani P, Schad H, Schreiber C, et al: Extravasation of albumin after cardiopulmonary bypass in newborns. J Cardiothorac Vascular Anesth 21:174-178, 2007

42. Stiller B, Sonntag J, Dahnert I, et al: Capillary leak syndrome in children who undergo cardiopulmonary bypass: Clinical outcome in comparison with complement activation and $\mathrm{C} 1$ inhibitor. Intensive Care Med 27:193-200, 2001

43. Seghaye MC, Grabitz RG, Duchateau J, et al: Inflammatory reaction and capillary leak syndrome related to cardiopulmonary bypass in neonates undergoing cardiac operations. J Thorac Cardiovasc Surg 112:687-697, 1996

44. Levy JH, Kelly AB: Inflammation and cardiopulmonary bypass. Can J Anaesth 40:1009-1015, 1993 
45. Fleck A, Raines G, Hawker F, et al: Increased vascular permeability: A major cause of hypoalbuminaemia in disease and injury. Lancet 1:781-784, 1985

46. Cox CS Jr, Allen SJ, Butler D, et al: Extracorporeal circulation exacerbates microvascular permeability after endotoxemia. J Surg Res 91:50-55, 2000

47. Liu SF, Ye X, Malik AB: Pyrrolidine dithiocarbamate prevents I-kappaB degradation and reduces microvascular injury induced by lipopolysaccharide in multiple organs. Mol Pharmacol 55:658-667, 1999

48. Yu P, Martin CM: Increased gut permeability and bacterial translocation in Pseudomonas pneumonia-induced sepsis. Crit Care Med 28:2573-2577, 2000

49. Dauber IM, Parsons PE, Welsh $\mathrm{CH}$, et al: Peripheral bypassinduced pulmonary and coronary vascular injury: Association with increased levels of tumor necrosis factor. Circulation 88:726-735, 1993

50. Koning NJ, Vonk AB, Vink H, et al: Side-by-side alterations in glycocalyx thickness and perfused microvascular density during acute microcirculatory alterations in cardiac surgery. Microcirculation 23: 69-74, 2016

51. De Backer D, Ortiz JA, Salgado D: Coupling microcirculation to systemic hemodynamics. Curr Opin Crit Care 16:250-254, 2010

52. Atasever B, Boer C, Goedhart P, et al: Distinct alterations in sublingual microcirculatory blood flow and hemoglobin oxygenation in on-pump and off-pump coronary artery bypass graft surgery. J Cardiothorac Vasc Anesth 25:784-790, 2011

53. Koning NJ, Vonk ABA, Meesters MI, et al: Microcirculatory perfusion is preserved during off-pump but not on-pump cardiac surgery. J Cardiothorac Vasc Anesth 28:336-341, 2014

54. Greenway CV, Lautt WW: Blood volume, the venous system, preload and cardiac output. Can J Physiol Pharmacol 64:383-387, 1986

55. Maas JJ, Pinsky MR, Aarts LP, et al: Bedside assessment of total systemic vascular compliance, stressed volume, and cardiac function curves in intensive care unit patients. Anesth Analg 115:880-887, 2012 